\title{
Saphenous vein homograft containing a valve as a right ventricle-pulmonary artery conduit in the modified Norwood operation
}

\author{
Arata Murakami, MD, Shinichi Takamoto, MD, Tetsuhiro Takaoka, MD, Jyotaro Kobayashi, MD, Katsuhide Maeda, MD, \\ Hiroo Takayama, MD, Noboru Motomura, MD, Tomohiro Murakawa, MD, and Minoru Ono, MD, Tokyo, Japan
}

W e report a case of hypoplastic left heart syndrome treated by means of the modified Norwood operation with a saphenous vein homograft containing a valve as an extracardiac right ventricle-pulmonary artery conduit (RV-PA conduit).

\section{Clinical Summary}

The modified Norwood operation was performed to treat hypoplastic left heart syndrome in a 7-day-old boy weighing $2.7 \mathrm{~kg}$. Preoperative echocardiography demonstrated aortic stenosis (aortic valve diameter, $2.0 \mathrm{~mm}$ ) and mitral stenosis (mitral valve diameter, $4.5 \mathrm{~mm}$ ) and a large secundum-type atrial septal defect, hypoplastic aortic arch, aortic coarctation, and mild-to-moderate tricuspid regurgitation. Ventilator support with $19 \%$ of inspired oxygen fraction and alprostadil (prostaglandin $\mathrm{E}_{1}$ ) administration were started on postnatal day 2 .

After median sternotomy, a 3.0-mm polytetrafluoroethylene (PTFE) graft was anastomosed to the right innominate artery as a perfusion line. Cardiopulmonary bypass was instituted by means of bicaval drainage, and another perfusion cannula was inserted into the descending aorta for the lower body perfusion. ${ }^{1}$ The right and left PAs were choked up, and a venting cannula was inserted. When the rectal temperature reached $32^{\circ} \mathrm{C}$, a vascular clamp was placed on the descending aorta, and the ductus arteriosus was ligated and divided. The ductal tissue in the isthmus was removed, and the main PA was divided at the bifurcation level. The systemic outflow tract was reconstructed without synthetic material, partly during isolated cerebral and myocardial perfusion and partly with the heart arrested. ${ }^{2}$ The right atrium was opened, and a wide interatrial communication was confirmed. An 8-mm vertical ventriculotomy was made on the right ventricular outflow tract, and a small amount of the muscle was resected. A saphenous vein homograft containing a valve with an external diameter of $4 \mathrm{~mm}$ (supplied by the University of Tokyo Tissue Bank, Tokyo, Japan) was thawed, and valve competence was checked. An obliquely cut

From the Department of Cardiothoracic Surgery, Faculty of Medicine, University of Tokyo, Tokyo, Japan.

Received for publication March 29, 2002; accepted for publication April 5, 2002.

Address for reprints: Arata Murakami, MD, Department of Cardiothoracic Surgery, Faculty of Medicine, University of Tokyo, 7-3-1, Hongou, Bunkyou-ku, Tokyo, 113-8655, Japan (E-mail: MURAKAMI-THO@h.utokyo.ac.jp).

J Thorac Cardiovasc Surg 2002;124:1041-2

Copyright $\odot 2002$ by The American Association for Thoracic Surgery

$0022-5223 / 2002 \$ 35.00+0 \quad \mathbf{1 2 / 5 4 / 1 2 6 4 7 0}$

doi: $10.1067 / \mathrm{mtc} .2002 .126470$ end was anastomosed to the ventriculotomy, the right atriotomy was closed, and the coronary arteries were reperfused. During rewarming, the distal end of the homograft was trimmed and connected to the bifurcation of the PA (Figure 1). The pump termination was smooth, with excellent hemodymanics. The pulmonary flow/systemic flow ratio at the operating room was calculated as 0.99: oxygen saturation of the arterial blood was $69 \%$, with a $21 \%$ inspired oxygen fraction; saturation of the blood taken from the superior vena cava was $40.5 \%$; and the pulmonary venous blood saturation was 99\%. A CV-0 PTFE suture was left in place around the homograft for possible adjustment of the conduit. The central venous pressure was $5 \mathrm{~mm} \mathrm{Hg}$, and the systemic systolic and diastolic blood pressures were $75 \mathrm{~mm} \mathrm{Hg}$ and $38 \mathrm{~mm} \mathrm{Hg}$, respectively. The sternum was split with a short segment of 7-mm endotracheal tube stent. The pump time was 201 minutes, and the myocardial ischemic time was 46 minutes. The procedure lasted 6 hours and 5 minutes. The patient's metabolic acidosis and hyperlactatenemia improved within 24 hours postoperatively. Perioperative care, including pulmonary flow/systemic flow adjustment by means of titration of sodium nitroprusside, conformed to that described in a published article. ${ }^{3}$

The postoperative course was stable, with satisfactory renal and liver function, and no neurologic deficits were detected. Echocardiography demonstrated trivial regurgitant signals in the homograft (Figure 2), and the patient is now waiting for the secondstage bidirectional Glenn shunt.

\section{Discussion}

Use of an RV-PA conduit as a source of the pulmonary flow instead of a PTFE Blalock-Taussig shunt has been reported in the Norwood operation. ${ }^{2,4}$ Imoto and coworkers ${ }^{2}$ reported higher postopertative systemic diastolic pressure in patients with an RV-PA nonvalved PTFE conduit and suggested that the higher systemic diastolic pressure leads to better coronary blood flow and results in stable circulation. However, the drawbacks of this technique (ie, the possible deleterious effects of right ventriculotomy and pulmonary regurgitation through the conduit) need to be carefully monitored. In our experience moderate regurgitant signals were detected during the acute postoperative phase. In the present case the valve in the saphenous vein homograft almost completely eliminated the pulmonary regurgitation, and the hemodynamics were better than those in the case with the nonvalved conduit.

Chronic rejection and long-term function of the homograft are concerns. Good long-term function and less thrombogenicity of saphenous vein homografts as a Blalock-Taussig shunt material have been reported.5,6 Close observation of valve function is mandatory. If any signs of stenosis are detected, an additional Blalock-Taussig shunt or early second-stage bidirectional Glenn shunt are options. 


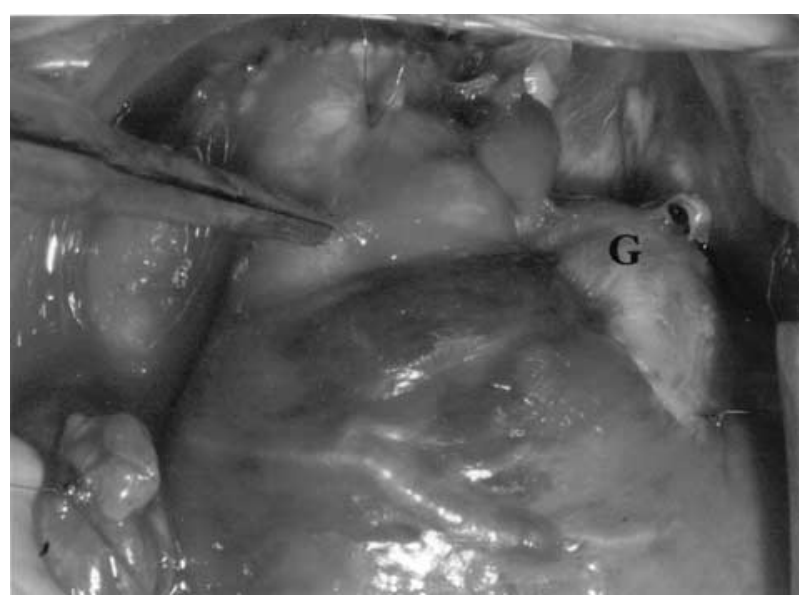

Figure 1. Proximal anastomosis of the saphenous vein homograft (G). The valve is located $6 \mathrm{~mm}$ distal to the proximal anastomosis.

In conclusion, use of a saphenous vein homograft containing a competent valve as an RV-PA conduit in the modified Norwood operation eliminates pulmonary regurgitation and leads to superior postoperative hemodynamics and an improved outcome.

We thank Ms Noriko Yoneda and Ms Sakiko Shibusawa for their help in shipping and thawing of the homograft.

\section{References}

1. Imoto Y, Kado H, Shiokawa Y, Fukae K, Yasui H. Norwood procedure without circulatory arrest. Ann Thorac Surg. 1999;68:559-61.

2. Imoto Y, Kado H, Shiokawa Y, Minami K, Yasui H. Experience with the Norwood procedure without circulatory arrest. J Thorac Cardiovasc Surg. 2001;122:879-82.

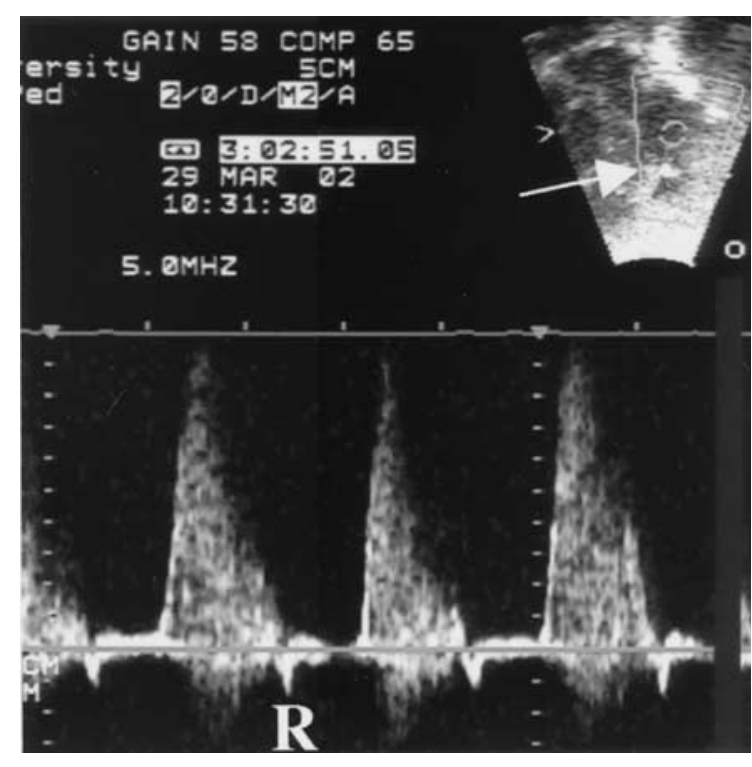

Figure 2. Postoperative echocardiography with Doppler flow mapping in the homograft demonstrated trivial regurgitant signals (R). The motion of the valve (arrow) could be observed.

3. Pearl JM, Nelson DP, Schwartz SM, Manning PB. First-stage palliation for hypoplastic left heart syndrome in the twenty-first century. Ann Thorac Surg. 2002;73:331-40.

4. Kishimoto H, Kawahira Y, Kawata H, Miura T, Iwai S, Mori T. The modified Norwood palliation on a beating heart. J Thorac Cardiovasc Surg. 1999;118:1130-2.

5. Bogats G, Kertesz E, Katona M, Toszegi A, Kovacs G. Modified Blalock-Taussig shunt using allograft saphenous vein: six years' experience. Ann Thorac Surg. 1996;61:58-62.

6. Tam VK, Murphy K, Parks J, Raviele AA, Vincent RN, Strieper M, et al. Saphenous vein homograft: a superior conduit for the systemic arterial shunt in the Norwood operation. Ann Thorac Surg. 2001;71: $1537-40$. 